\title{
Small Increase of Actual Physical Activity 6 Months After Total Hip or Knee Arthroplasty
}

\author{
Ingrid B. de Groot MSc, Hans J. Bussmann PhD, \\ Henk J. Stam MD, PhD, Jan A. Verhaar MD, PhD
}

Received: 14 December 2007 / Accepted: 6 May 2008/Published online: 28 May 2008

(C) The Author(s) 2008

\begin{abstract}
Limitation in daily physical activity is one of the reasons for total hip arthroplasty (THA) or total knee arthroplasty (TKA). However, studies of the effects of THA or TKA generally do not determine actual daily activity as part of physical functioning. We determined the effect of THA or TKA on patients' actual physical activity and body function (pain, stiffness), capacity to perform tasks, and self-reported physical functioning. We also assessed whether there are differences in the effect of the surgery between patients undergoing THA or TKA and whether the improvements vary between these different outcome measures. We recruited patients with longstanding end-stage osteoarthritis of the hip or knee awaiting THA or TKA. Measurements were performed before surgery and 3 and 6 months after surgery. Actual physical activity improved by $0.7 \%$. Patients' body function, capacity, and self-reported physical functioning also improved. The effects of the surgery on these aspects of physical functioning were similar for THA and TKA. The
\end{abstract}

Each author certifies that he or she has no commercial associations (eg, consultancies, stock ownership, equity interest, patent/licensing arrangements, etc) that might pose a conflict of interest in connection with the submitted article.

Each author certifies that his or her institution has approved the human protocol for this investigation, that all investigations were conducted in conformity with ethical principles of research, and that informed consent for participation in the study was obtained.

I. B. de Groot $(\bowtie)$, J. A. Verhaar

Department of Orthopaedics, Medicine University,

Erasmus Medical Center, PO Box 2040, 3000 CA Rotterdam,

The Netherlands

e-mail: i.b.degroot@erasmusmc.nl

H. J. Bussmann, H. J. Stam

Department of Rehabilitation, Medicine University,

Erasmus Medical Center, Rotterdam, The Netherlands effect on actual physical activity (8\%) was smaller than on body function $(80 \%-167 \%)$, capacity $(19 \%-36 \%)$, and self-reported physical functioning $(87 \%-112 \%)$. Therefore, in contrast to the large effect on pain and stiffness, patients' capacity, and their self-reported physical functioning, the improvement in actual physical activity of our patients was less than expected 6 months after surgery.

Level of Evidence: Level I, prospective study. See the Guidelines for Authors for a complete description of levels of evidence.

\section{Introduction}

Limitation in daily physical activity is one of the reasons for THA or TKA. However, some studies of the effects of THA or TKA do not include actual daily physical activity as an outcome. Two studies on other diseases suggest no or only weak relationships among actual physical activity, patients' capacity, and self-reported physical functioning $[13,37]$. This means actual physical activity is a distinct aspect of physical functioning. There is no doubt THA and TKA effectively alleviate pain and improve function for patients, but whether that translates into more actual physical activity is unclear.

We hypothesized that patients' actual physical activity, body function, capacity, and self-reported physical functioning would be markedly different after THA or TKA. We therefore specifically sought to determine the effect of THA or TKA 3 and 6 months after surgery on patients' (1) actual physical activity as measured with an activity monitor (primary research question); and (2) body function as measured by the WOMAC subscales pain and function, patients' capacity measured by the 6-MWT, a rising from chair test and a stair walk test, and self-reported physical 
functioning measured by the WOMAC function subscale, SF-36 function subscale, and the Physical Activity Scale for Individuals with Physical Disabilities (PASIPD). We also assessed whether (3) the effects of surgery differ between patients undergoing THA or TKA in actual physical activity, body function, capacity, and self-reported physical functioning; and (4) the improvements vary among these different outcome measures.

\section{Materials and Methods}

We recruited and prospectively followed 84 patients with end-stage osteoarthritis (OA) of the hip or knee awaiting THA or TKA. All patients had long-standing end-stage OA of the hip or knee refractory to nonoperative treatment and were scheduled for THA or TKA between April 2004 and May 2006. All data were collected before surgery ( $\mathrm{t} 0$ ), 3 months postsurgery (t3), and 6 months postsurgery (t6). We excluded patients (1) older than 80 years $(\mathrm{n}=15)$; (2) who were wheelchair-bound or not living independently $(\mathrm{n}=2)$; (3) with comorbidities other than OA that could affect the level of actual physical activity $(n=14)$; this was determined by questions about general health and the presence and/or absence of diseases; (4) living more than 1.5 hours away from the medical center $(n=10)$; (5) with insufficient command of the Dutch language (spoken or written) $(n=4)$; (6) with OA in the contralateral hip or knee requiring surgery within 6 months $(\mathrm{n}=11)$; $(7)$ not willing to sign informed consent $(\mathrm{n}=1)$; and (8) who were questioned whether they would be available for followup measurements $(n=3)$. Among the 84 patients recruited, four with inadequate followup data (3-month and/or 6month data missing) were excluded, leaving 80 for the study (Table 1). With a power of $80 \%$ and a significance level of $0.05,72$ subjects would be needed to show a minimum clinically relevant improvement of $10 \%$ in the primary outcome parameter, movement-related activity, between baseline and 6 months after treatment. The mean age of the patients with OA was 61.8 years (standard deviation, 11.2). The Medical Ethics Committee of the Erasmus Medical Center approved the study and all patients signed informed consent.

During their initial visit to the outpatient clinic before surgery, we approached all patients and informed them about the study. All received verbal and written information about the study and could indicate whether they wanted to participate or they could decide later after examining the written information. As noted, the inclusions and exclusions left us with 80 patients.

We collected data during the checkup before surgery. The mean duration from the checkup until surgery was 43 days (median, 30 days). Data were collected on age, gender, height and weight (wearing indoor clothing without shoes), affected joint, and grade of OA. Patients with hip OA only differed $(\mathrm{p}=0.000)$ from those with knee OA with regard to body mass index. We also obtained data on different aspects of physical functioning, ie, patients' actual physical activity, function, capacity, and perceived physical functioning.

One experienced reader (JV), who was unaware of the clinical status of the patients, graded the preoperative radiographs of the hips and knees using the Kellgren and Lawrence grading system in five grades (from 0 to 4 ) $[19,20]$.

The Activity Monitor (AM) is based on long-term ambulatory monitoring of signals from body-fixed accelerometers. From these signals, it is possible to detect a set of movement-related activities (eg, walking, cycling), body postures (eg, sitting and standing), and changes in body posture (eg, sit-to-stand movement) [4-8]. We performed measurements during 48 hours with the AM during 2

Table 1. Preoperative characteristics

\begin{tabular}{|c|c|c|c|c|}
\hline Characteristics & Total OA Group $(\mathrm{n}=80)$ & Hip OA $(n=36)$ & Knee OA $(\mathrm{n}=44)$ & $\mathrm{p}$ Value \\
\hline Age (years) & $61.8 \pm 11.2$ & $61.5 \pm 12.8$ & $62.1 \pm 9.7$ & 0.818 \\
\hline Gender (women; \%) & 58.8 & 63.9 & 54.5 & 0.401 \\
\hline Body mass index $\left(\mathrm{kg} / \mathrm{m}^{2}\right)$ & $29.6 \pm 5.5$ & $26.6 \pm 4.2$ & $32.1 \pm 5.3$ & 0.000 \\
\hline Side of surgery (left; \%) & 48.8 & 52.8 & 45.5 & 0.517 \\
\hline \multirow[t]{2}{*}{ Indication for surgery (number; \%) } & & Primary OA: 32 (88.9) & Primary OA: 40 (90.9) & \\
\hline & & Secondary OA: 4 (11.1) & Secondary OA: 4 (9.1) & \\
\hline \multirow[t]{5}{*}{ Kellgren and Lawrence (number; \%) } & & No OA : $0(0)$ & No OA: $0(0)$ & \\
\hline & & Doubtful: 2 (5.6) & Doubtful: $0(0)$ & \\
\hline & & Mild: 2 (5.6) & Mild: 2 (4.5) & \\
\hline & & Moderate: 10 (27.8) & Moderate: 13 (29.5) & \\
\hline & & Severe: $22(61.1)$ & Severe: 29 (65.9) & \\
\hline
\end{tabular}

Values are mean \pm standard deviation unless otherwise indicated; $\mathrm{OA}=$ osteoarthritis. 


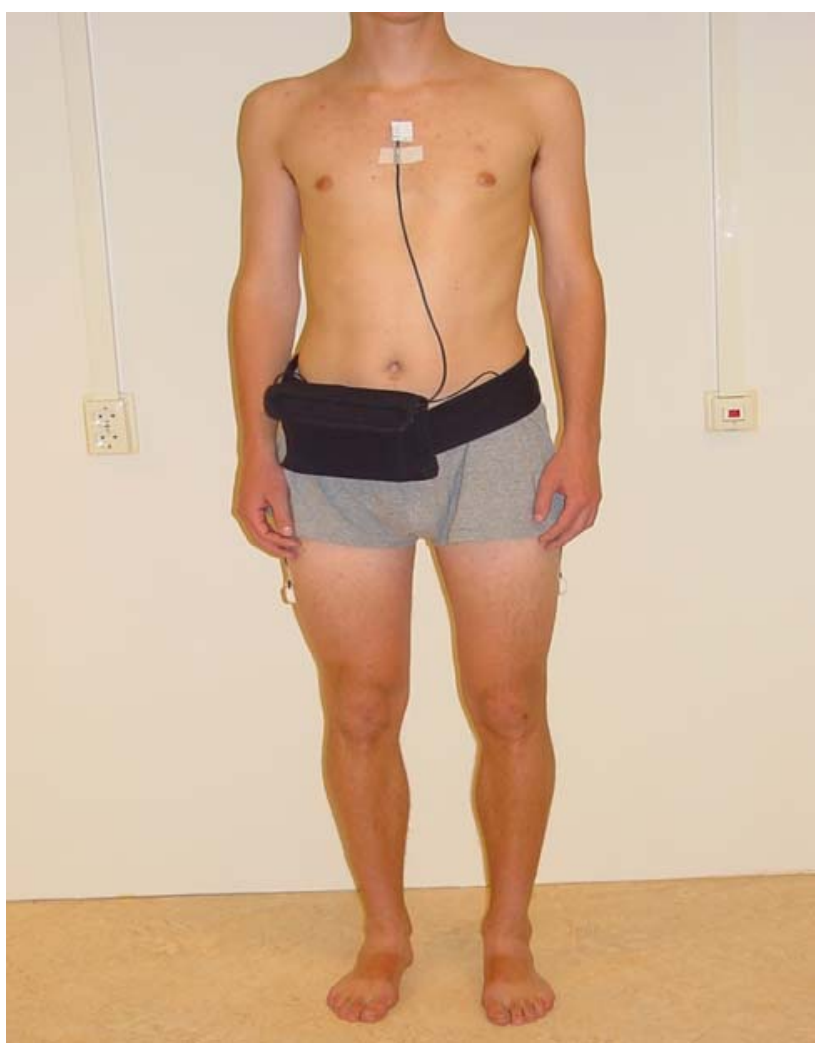

Fig. 1 A subject wearing the activity monitor with accelerometers at the thighs and trunk is shown.

consecutive weekdays (from Monday to Wednesday or from Wednesday to Friday). To avoid bias, the principles of the AM were explained to the participants only after the measurements were made. All participants agreed with this procedure. Validity studies show the AM is valid to quantify movement-related activities and body postures [4, $6,36]$. The AM is described in more detail elsewhere [6]. In short, three accelerometers were used in the following configurations: one sensor on the sternum and one sensor on each thigh (standard configuration) (Fig. 1). Data from the AM measurement were calculated per day (24-hour period) and averaged over the 2 measurement days. The level of actual physical activity was expressed as the percentage activity during a 24-hour period.

The WOMAC consists of three dimensions: pain (five items), stiffness (two items), and physical functioning (17 items) [3]. The 5-point Likert version of the WOMAC was used. The WOMAC is reliable and responsive and validated in Dutch [31]. In this domain, the pain and stiffness subscales were used.

The 6-minute-walk test was performed to quantify walking ability. It is a valid and inexpensive clinical tool that involves recording the distance participants cover while walking indoors at their own speed for 6 minutes [9, 15]. It has good test-retest reliability and has been used to measure the effectiveness of interventions in populations with hip or knee OA [16, 24, 25, 28, 30].

To investigate stairclimbing, the time required to ascend five steps, turn around, and descend five steps was used. This stairclimbing task has good test-retest reliability [29].

Various methods have been used to determine how well older adults can rise from a chair [14, 18, 26, 32, 34]. We asked patients to complete five repetitive sit-to-stand movements as quickly as possible without using their arms, if possible. The score was the time needed to perform the test. The sit-to-stand test has been used for people with arthritis and is a valid test [27].

The PASIPD evaluates the physical activity and is a modification of the Physical Activity Scale for the Elderly. The questionnaire requests the number of days a week and hours daily (categories) of participation in recreational, household, and occupational activities during the past 7 days [40]. Washburn et al. [40] reported supportive results for construct validity and Van der Ploeg et al. [38] concluded the criterion validity is comparable to wellestablished self-report physical activity questionnaires from the general population. The test-retest reliability Spearman correlation of the PASIPD was 0.77 [38].

We recorded the physical function subscales of the SF$36[1,39]$ and WOMAC [3]. The SF-36 is a generic health status questionnaire and is widely used, reliable, and validated in Dutch $[1,39]$. Function of the hip or knee also was assessed by the Harris hip score [33] and the Knee Society clinical rating scale [17], which are instruments used worldwide to assess patients undergoing total joint arthroplasty of the hip or knee.

Surgery was performed in a clean air operating room equipped with vertical laminar airflow, and the team used body exhaust systems. For THA, a posterolateral approach was performed with posterior capsular repair. For THA, a central skin and medial capsular incision was used. All patients had second-generation cephalosporin at induction of anesthesia followed by two additional doses. For the first 24 hours postoperatively, prophylactically, low-molecularweight heparin was administered for deep vein thrombosis during the patients' in-hospital stays. This was continued after discharge for 6 weeks. For TKA, numerous procedures were performed using computer navigation (Brainlab, Feldkirchen, Germany).

Patients underwent routine postoperative rehabilitation. They were mobilized early with full weightbearing as tolerated. After surgery, all patients received physical therapy as long as deemed necessary. In the majority of patients, physical therapy was limited to the first 6 weeks postoperatively.

We first established whether the variables had a normal distribution using the normality Kolmogorov-Smirnov test. We computed either means and standard deviations or 
median and range based on the findings of the normality test. The differences between preoperative and postoperative measurements were evaluated by the dependent $t$-test (when the variables were normally distributed) or by the Wilcoxon test (when the variables were not normally distributed). Analysis was performed using SPSS 10.1 for Windows (SPSS Inc, Chicago, IL).

\section{Results}

For the total patient group, the mean percentage of movement-related activity was $0.7 \%$ higher $(p=0.03)$ 6 months after surgery compared with preoperatively (Table 2). This is an improvement from 121 minutes preoperatively to 131 minutes 6 months after surgery. Patients with THA or TKA had more $(\mathrm{p}=0.01)$ sit-tostand movements 6 months postsurgery compared with before surgery.

Compared with before surgery, there was a reduction in pain $(\mathrm{p}<0.001)$ and stiffness $(\mathrm{p}<0.001)$, and an improvement $(\mathrm{p}<0.001)$ in the 6-minute-walk distance at t3 3 and t6 (Table 3). Patients needed less time to perform stair walking and rising from a chair 3 and 6 months after surgery, and patients also reported their physical functioning and actual physical activity (subjective) as improved. Similar data were found for the two subgroups. Between $\mathrm{t} 0$ and $\mathrm{t} 3$, the effect of pain and stiffness was greater $(p=0.04)$ for patients undergoing THA. Compared with before surgery, the changes at $t 3$ and t 6 on rising from a chair and self-reported physical functioning (WOMAC) were greater $(p=0.03$ and $p=0.03)$ for patients undergoing THA than for patients undergoing TKA.

Three and 6 months after surgery, there were no improvements in any of the parameters of the AM compared with before surgery in the THA and TKA groups. Also, there were no differences in the changes between the two groups.

The changes in actual physical activity between the data before surgery and followup data are smaller than the changes in the other three aspects of physical functioning among these measurements (patients' function, capacity, and self-reported physical functioning) (Fig. 2).

\section{Discussion}

Limitation in daily physical activity is one of the reasons for THA or TKA. However, some studies on the outcomes after THA or TKA do not determine actual daily activity as part of physical functioning. Based on the literature, we hypothesized patients' actual physical activity, body

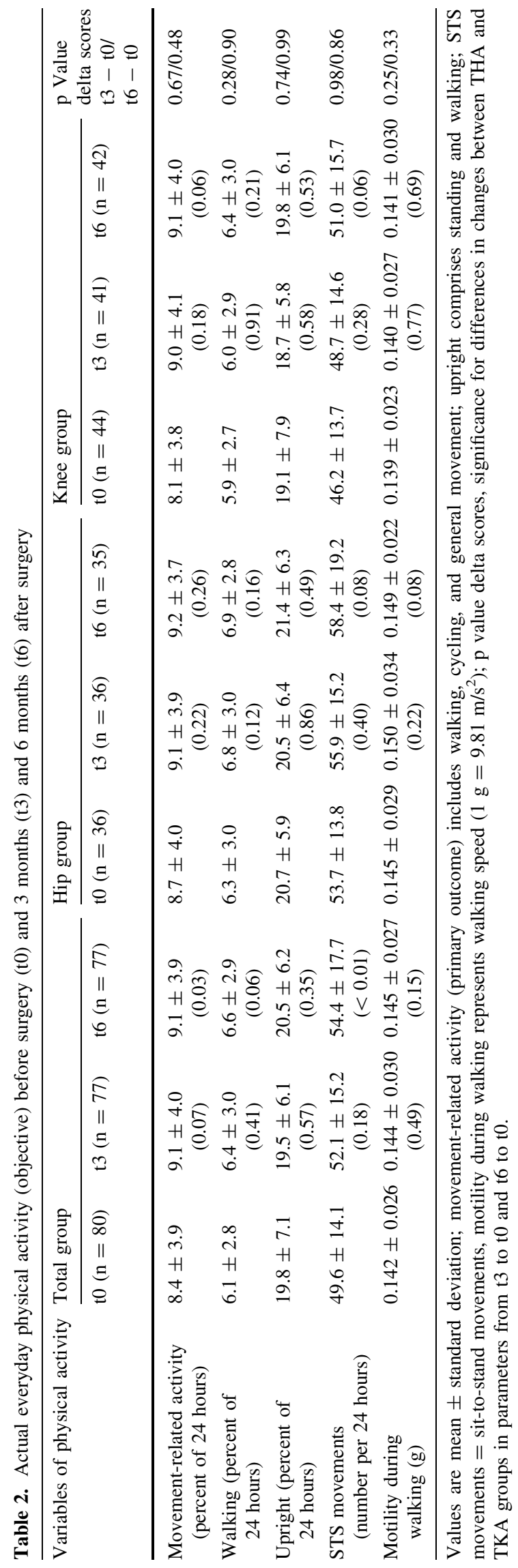




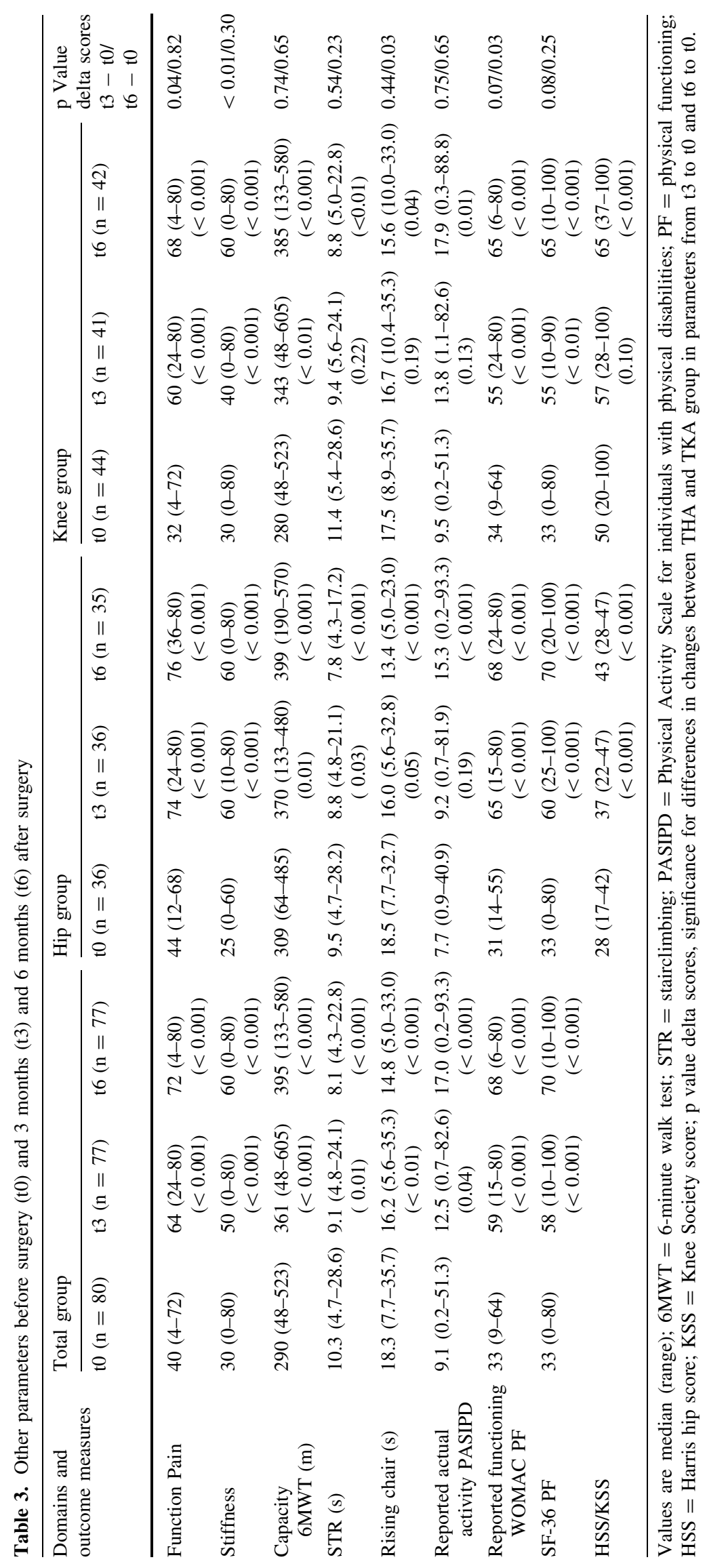




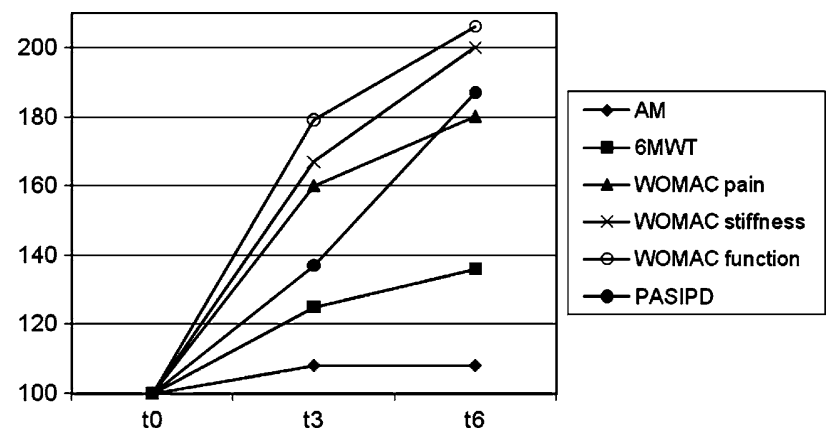

Fig. 2 A comparison of proportion of actual physical activity, function, capacity, and perceived physical functioning before ( $\mathrm{t} 0$ ) and after surgery ( $\mathrm{t} 3$ and $\mathrm{t} 6$ ) is shown. $\mathrm{AM}=$ Activity Monitor; $6 \mathrm{MWT}=6$-minute-walk test; $\mathrm{PF}=$ physical functioning; PASIPD $=$ Physical Activity Scale for individuals with physical disabilities.

function, capacity, and perceived physical functioning would be markedly different after THA or TKA. We therefore determined the effect of THA or TKA on patients' (1) actual physical activity (primary research question); (2) body function (pain, stiffness, and muscle strength), capacity to perform tasks, and self-reported physical functioning. We also assessed whether (3) there are substantial differences in effect of surgery between patients having THA or TKA in actual physical activity, body function, capacity, and self-reported physical functioning; and (4) the improvements vary between these different outcome measures.

This study has some limitations. First, the study group was relatively small. In the total patient group, there were differences on all outcome measurements among the three measurement times. For the subgroups, however, we observed no differences in AM outcome parameters. This suggests the study could be underpowered. A larger subgroup population probably would have shown differences between the measurement moments; however, we question whether these differences would be clinically relevant. We therefore believe that our conclusions would not change. Second, the followup may be too short to show relevant changes in actual activity level of the patients. However, most of the changes in physical functioning occur within 6 months [11, 35]. Kennedy et al. reported greatest improvements during the first 12 weeks after TKA and that slower improvements continued to occur from 12 to 26 weeks [21]. We believe after 26 weeks, some improvement may occur, but we believe only a limited improvement of physical functioning may be expected after the first 6 months. Future research should examine the long-term impact of THA or TKA on actual physical activity. Third, the THA and TKA groups differed regarding body mass index. Although we did not examine which factors in addition to type of surgery (hip or knee) influence the effect of the surgery, we realize body mass index may be an influence. Other factors that may influence the effect of surgery include the number of physical therapy treatments, whether a patient lives alone, and whether a patient uses pain medication. We did not register these factors, because the aim of our study was not to describe the determinants of recovery. Fourth, it has been suggested at least 4 days of activity monitoring are needed to characterize an individual's habitual activity pattern. However, we are convinced 48 hours sampling is adequate for comparison at the group level. Finally, some subjects reported the AM was not comfortable to wear during daily activities or during the night. Because this discomfort probably was experienced before and after surgery, we believe this did not influence the conclusions of this study.

When comparing the actual physical activity before and after treatment in the total group, the percentage of movement-related activities and the number of sit-to-stand movements improved 6 months after surgery. The percentage of movement-related activities increased by $0.7 \%$ and the number of sit-to-stand movements by $9.7 \%$. The changes we found suggest 6 months after surgery, the activity level had not approached that of healthy subjects, who are approximately $11 \%$ active per day [10]. Therefore, the influence of surgery on the objectively measured actual physical activity level was less than expected. However, the percentage of patients' self-reported improvement in actual physical activity measured by the PASIPD increased by $86 \%$. Therefore, there seems to be a discrepancy between self-reported actual physical activity and the objectively measured actual physical activity. It is possible many patients had OA for numerous years and had adapted their lifestyle to the limitations caused by the disease. It may take longer for them to readjust to a better functioning joint and to adopt a more active lifestyle. The 6-month followup may be too short to adequately show clinically relevant changes in the patients' actual activity level. However, it may be questioned whether patients would change their lifestyle spontaneously 6 months after surgery, when most rehabilitation programs have stopped. Another reason for the relatively minor changes in the actual physical activity level before and after surgery may be the actual physical activity level before the surgery. De Groot et al. [10] reported many patients with end-stage OA of the hip or knee maintain a relatively high activity level before surgery, despite pain and limitations, so less extreme changes after surgery are expected. Because patients reported many limitations in their capacity and physical functioning before surgery, it is not surprising they reported greater changes after surgery for these aspects of physical functioning.

Our findings regarding the patients' body function, capacity, and self-reported physical functioning are in line 
with those of other studies [2, 12, 21, 22]. Considerable pain reduction has been reported by others [2, 12]. An increase in the 6-minute-walk distance, improvement in stairclimbing, and better reported physical functioning have been reported $[2,12]$.

The type of surgery did not influence actual physical activity, but the effect was present in the other aspects of physical functioning. It has been reported that the effect of THA on pain and physical functioning is greater than the effect of TKA [2, 23]. Patients undergoing THA experienced a larger reduction in pain and stiffness than patients undergoing TKA 3 months after surgery; however, this difference was no longer was present 6 months after surgery. The improved performance in the rising-from-a-chair capacity test and perceived improvement in physical functioning (WOMAC PF) were greater for patients undergoing THA than for patients undergoing TKA 6 months after surgery. However, no such difference was observed in actual physical activity 6 months after surgery. The impact of TKA on actual activity is the same as that of THA.

Our data suggest the effect of THA or TKA on actual activity was not only small, but even smaller than the effect on function, capacity, and perceived limitations. The patients did not adopt a more active lifestyle despite improved function, capacity, and self-reported physical functioning 6 months after surgery. After surgery, patients' capacity during performance tests improved, whereas their activity level remained constant. It is possible that before surgery, there is a discrepancy between patients' capacity and their actual physical activity; patients' capacity is lower than or close to their actual physical activity, which may be related to overload such as pain, fatigue, etc. After surgery, because of increased capacity, the discrepancy between capacity and actual physical activity becomes smaller. The patients perform their actual activity after surgery with less pain and less perceived limitations than before. Perhaps the patients are satisfied knowing they can do more if they want to without having to perform the actual activity. For patients with Guillain-Barré syndrome, similar results were found, although the evaluated intervention was a training program instead of surgery; patients' capacity and perceived physical functioning improved but did not lead to a more active lifestyle [13]. Garssen et al. [13] also suggested raising the level of daily physical activity was not the initial adaptation strategy for these patients, and this also may apply to our study population. Decreasing pain and discomfort may be more important for them than increasing their actual physical activity, which they kept at a relatively high level before surgery. Overall, our study shows that improvements in physical functioning vary from aspect to aspect. Clinicians should be aware that postoperative evaluation of effect is dependent on which aspect is being measured.
We found that the effects of THA or TKA on patients' function, capacity, and self-reported physical functioning were larger than the effect on patients' actual physical activity. Patients did not adopt a more active lifestyle 6 months after surgery despite improvements in other aspects of physical functioning. When assessing the impact of THA or TKA, physicians bear this in mind and consider which aspect of physical functioning patients and they are most interested in achieving.

Acknowledgments We thank all patients who participated in this study.

Open Access This article is distributed under the terms of the Creative Commons Attribution Noncommercial License which permits any noncommercial use, distribution, and reproduction in any medium, provided the original author(s) and source are credited.

\section{References}

1. Aaronson NK, Muller M, Cohen PD, Essink-Bot ML, Fekkes M, Sanderman R, Sprangers MA, te Velde A, Verrips E. Translation, validation, and norming of the Dutch language version of the SF36 Health Survey in community and chronic disease populations. J Clin Epidemiol. 1998;51:1055-1068.

2. Bachmeier CJ, March LM, Cross MJ, Lapsey HM, Tribe KL, Courtenay BG, Brooks PM; Arthritis Cost and Outcome Project Group. A comparison of outcomes in osteoarthritis patients undergoing total hip and knee replacement surgery. Osteoarthritis Cartilage. 2001;9:137-146.

3. Bellamy N, Buchanan WW, Goldsmith $\mathrm{CH}$, Campbell J, Stitt LW. Validation study of WOMAC: a health status instrument for measuring clinically important patient relevant outcomes to antirheumatic drug therapy in patients with osteoarthritis of the hip or knee. J Rheumatol. 1988;15:1833-1840.

4. Bussmann HB, Reuvekamp PJ, Veltink PH, Martens WL, Stam HJ. Validity and reliability of measurements obtained with an "activity monitor" in people with and without a transtibial amputation. Phys Ther. 1998;78:989-998.

5. Bussmann JB, Hartgerink I, van der Woude LH, Stam HJ. Measuring physical strain during ambulation with accelerometry. Med Sci Sports Exerc. 2000;32:1462-1471.

6. Bussmann JB, Martens WL, Tulen JH, Schasfoort FC, van den Berg-Emons HJ, Stam HJ. Measuring daily behavior using ambulatory accelerometry: the Activity Monitor. Behav Res Methods Instrum Comput. 2001;33:349-356.

7. Bussmann JB, Tulen JH, van Herel EC, Stam HJ. Quantification of physical activities by means of ambulatory accelerometry: a validation study. Psychophysiology. 1998;35:488-496.

8. Bussmann JB, van de Laar YM, Neeleman MP, Stam HJ. Ambulatory accelerometry to quantify motor behaviour in patients after failed back surgery: a validation study. Pain. 1998;74:153-161.

9. Cahalin LP, Mathier MA, Semigran MJ, Dec GW, DiSalvo TG. The six-minute walk test predicts peak oxygen uptake and survival in patients with advanced heart failure. Chest. 1996;110: 325-332.

10. de Groot IB, Bussmann JB, Stam HJ, Verhaar JA. Actual everyday physical activity in patients with end-stage hip or knee osteoarthritis compared with healthy controls. Osteoarthritis Cartilage. 2008;16:436-442. 
11. Ethgen O, Bruyere O, Richy F, Dardennes C, Reginster JY. Health-related quality of life in total hip and total knee arthroplasty: a qualitative and systematic review of the literature. J Bone Joint Surg Am. 2004;86:963-974.

12. Fitzgerald JD, Orav EJ, Lee TH, Marcantaonio ER, Poss R, Goldman L, Mangione CM. Patient quality of life during the 12 months following joint replacement surgery. Arthritis Rheum. 2004;51:100-109.

13. Garssen MP, Bussmann JB, Schmitz PI, Zandbergen A, Welter TG, Merkies IS, Stam HJ, van Doorn PA. Physical training and fatigue, fitness, and quality of life in Guillain-Barré syndrome and CIDP. Neurology. 2004;63:2393-2395.

14. Guralnik JM, Simonsick EM, Ferrucci L, Glynn RJ, Berkman LF, Blazer DG, Scherr PA, Wallace RB. A short physical performance battery assessing lower extremity function: association with self-reported disability and prediction of mortality and nursing home admission. J Gerontol. 1994;49:M85-94.

15. Guyatt GH, Sullivan MJ, Thompson PJ, Fallen EL, Pugsley SO, Taylor DW, Berman LB. The 6-minute walk: a new measure of exercise capacity in patients with chronic heart failure. Can Med Assoc J. 1985;132:919-923.

16. Harada ND, Chiu V, Stewart AL. Mobility-related function in older adults: assessment with a 6-minute walk test. Arch Phys Med Rehabil. 1999;80:837-841.

17. Insall JN, Dorr LD, Scott RD, Scott WN. Rationale of the Knee Society clinical rating system. Clin Orthop Relat Res. 1989;248: 13-14.

18. Judge JO, Schechtman K, Cress E. The relationship between physical performance measures and independence in instrumental activities of daily living. The FICSIT Group. Frailty and Injury: Cooperative Studies of Intervention Trials. J Am Geriatr Soc. 1996;44:1332-1341.

19. Kellgren JH, Lawrence JS. Radiological assessment of osteoarthrosis. Ann Rheum Dis. 1957;16:494-502.

20. Kellgren JH, Lawrence JS. Radiological assessment of rheumatoid arthritis. Ann Rheum Dis. 1957;16:485-493.

21. Kennedy DM, Stratford PW, Hanna SE, Wessel J, Gollish JD. Modeling early recovery of physical function following hip and knee arthroplasty. BMC Musculoskelet Disord. 2006;7:100.

22. Kennedy DM, Stratford PW, Riddle DL, Hanna SE, Gollish JD. Assessing recovery and establishing prognosis following total knee arthroplasty. Phys Ther. 2008;88:22-32.

23. Kiebzak GM, Vain PA, Gregory AM, Mokris JG, Mauerhan DR. SF-36 general health status survey to determine patient satisfaction at short-term follow-up after total hip and knee arthroplasty. J South Orthop Assoc. 1997;6:169-172.

24. Kovar PA, Allegrante JP, MacKenzie CR, Peterson MG, Gutin B, Charlson ME. Supervised fitness walking in patients with osteoarthritis of the knee: a randomized, controlled trial. Ann Intern Med. 1992;116:529-534.

25. Kreibich DN, Vaz M, Bourne RB, Rorabeck CH, Kim P, Hardie R, Kramer J, Kirkley A. What is the best way of assessing outcome after total knee replacement? Clin Orthop Relat Res. 1996;331:221-225.
26. Lord SR, Murray SM, Chapman K, Munro B, Tiedemann A. Sit-to-stand performance depends on sensation, speed, balance, and psychological status in addition to strength in older people. J Gerontol A Biol Sci Med Sci. 2002;57:M539-543.

27. Newcomer KL, Krug HE, Mahowald ML. Validity and reliability of the timed-stands test for patients with rheumatoid arthritis and other chronic diseases. J Rheumatol. 1993;20:21-27.

28. Peterson MG, Kovar-Toledano PA, Otis JC, Allegrante JP, Mackenzie CR, Guting B, Kroll MA. Effect of a walking program on gait characteristics in patients with osteoarthritis. Arthritis Care Res. 1993;6:11-16.

29. Rejeski WJ, Ettinger WH Jr, Martin K, Morgan T. Treating disability in knee osteoarthritis with exercise therapy: a central role for self-efficacy and pain. Arthritis Care Res. 1998;11:94-101.

30. Rejeski WJ, Ettinger WH Jr, Schumaker S, James P, Burns R, Elam JT. Assessing performance-related disability in patients with knee osteoarthritis. Osteoarthritis Cartilage. 1995;3:157-167.

31. Roorda LD, Jones CA, Waltz M, Lankhorst GJ, Bouter ML, van der Eijken JW, Willems WJ, Heyligers IC, Voaklander DC, Kelly $\mathrm{KD}$, Suarez-Almazor ME. Satisfactory cross cultural equivalence of the Dutch WOMAC in patients with hip osteoarthritis waiting for arthroplasty. Ann Rheum Dis. 2004;63:36-42.

32. Seeman TE, Charpentier PA, Berkman LF, Tinetti ME, Guralnik JM, Albert M, Blazer D, Rowe JW. Predicting changes in physical performance in a high-functioning elderly cohort: MacArthur studies of successful aging. J Gerontol. 1994;49:M97-108.

33. Soderman P, Malchau H. Is the Harris hip score system useful to study the outcome of total hip replacement? Clin Orthop Relat Res. 2001;384:189-197.

34. Thapa PB, Gideon P, Fought RL, Kormicki M, Ray WA. Comparison of clinical and biomechanical measures of balance and mobility in elderly nursing home residents. J Am Geriatr Soc. 1994;42:493-500.

35. Towheed TE, Hochberg MC. Health-related quality of life after total hip replacement. Semin Arthritis Rheum. 1996;26:483-491.

36. van den Berg-Emons HJ, Bussmann JB, Balk AH, Stam HJ. Validity of ambulatory accelerometry to quantify physical activity in heart failure. Scand J Rehabil Med. 2000;32:187-192.

37. van den Berg-Emons RJ, Bussmann JB, Balk AH, Stam HJ. Factors associated with the level of movement-related everyday activity and quality of life in people with chronic heart failure. Phys Ther. 2005;85:1340-1348.

38. van der Ploeg HP, Streppel KR, van der Beek AJ, van der Woude LH, Vollenbroek-Hutten M, van Mechelen W. The Physical Activity Scale for Individuals with Physical Disabilities: testretest reliability and comparison with an accelerometer. $J$ Phys Act Health. 2007;4:96-100.

39. Ware JE Jr, Sherbourne CD. The MOS 36-item short-form health survey (SF-36). I. Conceptual framework and item selection. Med Care. 1992;30:473-483.

40. Washburn RA, Zhu W, McAuley E, Frogley M, Figoni SF. The physical activity scale for individuals with physical disabilities: development and evaluation. Arch Phys Med Rehabil. 2002;83: 193-200. 